\title{
SISTEM INFORMASI APLIKASI PELAYANAN PANTI SOSIAL
}

\author{
Roida Pakpahan'1, Yuni Fitriani², Mahdiyyah ${ }^{3}$ \\ Sistem Informasi \\ Universitas Bina Sarana Informatika \\ www.bsi.ac.id \\ roida.rkh@bsi.ac.id ${ }^{1}$, \\ yuni.yfi@bsi.ac.id², \\ mahdiyyah@gmail.com ${ }^{3}$
}

\begin{abstract}
Social institutions function to provide skills training to women who were previously commercial sex workers to have skills so they are able to find decent jobs or able to build independent businesses. At present the Harapan Mulia Social Institution has used an information system to manage the data of the assisted citizens but the use of its information system still has several disadvantages including; the program does not have a data search facility that has been fostered so that the search for data of the assisted citizens will take a long time, the certificate of the assisted citizens is not systemic so that the printed certificate will take a long time because the staff will manually retrieve the data again. This study aims to design information systems using software development using the waterfall method by adding data searches on applications and storing certificates in the system to speed up the work process of employees.
\end{abstract}

Keywords : Social Institution, Service System, Assisted Citizens

Intisari-Panti sosial berfungsi untuk memberikan pelatihan keterampilan pada perempuan yang sebelumnya menjadi pekerja seks komersial agar memiliki ketrampilan sehingga mampu mencari pekerjaan yang layak atau mampu membangun usaha mandiri. Pada saat ini Panti Sosial Harapan Mulia sudah menggunakan sistem informasi untuk mengelola data warga binaan namun penggunaan sistem informasinya masih memiliki beberapa kekurangan diantaranya; program tidak memiliki fasilitas pencarian data warga binaan sosial yang telah dibina sehingga untuk mencari data warga binaan akan membutuhkan waktu yang lama, sertifikat warga binaan tidak tersistem sehingga untuk mencetak sertifikat warga binaan akan membutuhkan waktu yang lama karena staff akan mengentri data kembali secara manual. Penelitian ini bertujuan merancang sistem informasi dengan menggunakan pengembangan perangkat lunak dengan menggunakan metode waterfall dengan penambahan pencarian data pada aplikasi dan penyimpanan sertifikat dalam sistem untuk mempercepat proses kerja karyawan.

Kata Kunci: Panti Sosial, Sistem Pelayanan, Warga Binaan

\section{PENDAHULUAN}

Keberadaan panti sosial pada hakekatnya sangat membantu pemerintah untuk menyiapkan masyrakat yang memiliki keterampilan guna meningkatkan pendapatan ekonomi tererutama perempuan yang menghuni panti sosial. Pada khususya perempuan yang menjadi penghuni panti sosial yang memiliki latar belakang sebagai pekerja seks komersial. Pekerja seks komersial adalah seseorang yang menjual jasanya untuk melakukan hubungan seksual demi uang. (Destrianti \& Harnani, 2018). Pekerja seks komersial merupakan pekerjaan yang dilakukan untuk mengatasi masalah kesulitan ekonomi dan membantu keluarga (Susetyo \& Sudiantara, 2015).

Pada umumnya alasan utama dari terjunnya seorang menjadi perkerja seks komersial disebabkan karna masalah ekonomi, pendidikan yang terbatas dan cara pandamg mereka melihat pekerja seks komersial merupakan salah satu cara untuk memperoleh uang yang banyak.

Disisi lain Pemerintah pada umumnya memberikan pembinaan untuk para kerja seks komersial tersebut melalui Dinas sosial dan Panti Sosial Bina Karya Wanita Harapan Mulia merupakan salah satu tempat pelayanan sosial dibawah naungan Dinas Sosial. (Soebijoto, 2018) mengatakan sebagian dari warga binaan Panti Sosial Harapan Mulia sebelumnya merupakan pekerja seks komersial dan berada dipanti tersebut karena faktor pendidikan yang kurang, minimnya ekonomi dan diacuhkan keluarga.

Saati ini pelayanan warga bina karya pada Panti Sosial Harapan Mulia memiliki 80 warga binaan. Pegawai dan pramu sosial Harapan Mulia membantu warga bina sosial dalam mengembangkan keterampilan yang mereka miliki. 
Umumnya tenaga pelayananan sosial melakukan identifikasi untuk memastikan bahwa para calon warga binaan tersebut apakah latar belakangnya benar-benar bekerja sebagai pekerja seks komersial. Dan sebelum diterima sebagai warga bina sosial dilakukan tahap seleksi terlebih dahulu untuk mengetahui kemampuan atau keterampilan yang dimiliki oleh calon binaan, keterampilan tersebut mulai dari tata boga, tata rias, membuat pernak-pernik, membuat alas kaki, membuat telur asin dan membuat anyaman rotan dan setelah proses seleksi selesai setiap warga binaan ditempatkan di asrama dan dibimbing selama 6 (enam) bulan untuk mengikuti pelatihan keterampilan yang telah dipilih diantaranya pelatihan tata boga, hasta karya, salon kecantikan hingga menjahit.

Dan setelah warga binaan telah selesai mengikuti pelatihan, warga binaan akan melakukan praktek dan mengikuti ujian ketertampilan dan selanjutnya akan dibimbing lebih lanjut untuk membuka usaha sendiri secara mandiri atau didalurkan ketempat kerja yang sesuai dengan ketampilan yang telah dimiliki.

Saat ini untuk mengolah data warga bina karya dipanti sosial Harapan Mulia sudah menggunakan sistem informasi panti sosial, namun demikian sistem masih memiliki kekurangan dalam program, yaitu pertama, tidak adanya fasiltas pencarian data sehingga untuk mencari data warga binaan akan membutuhkan waktu yang lama, kedua sertifikat warga binaan tidak disimpan didalam sistem oleh karena itu penulis melakukan pengembangan sistem agar proses pencarian data dan penyimpanan data sertifikat dan pembuatan sertifikat bisa lebih mudah dilakukan.

Penyelenggaraan sertifikat elektronik yang digunakan dalam kegiatan transaksi elektronik agar mendukung tumbuh-kembangnya industri sertifikat elektronik di Indonesia (Setiawan, 2015) Penelitian ini bertujuan merancang sistem informasi pelayanan menggunakan metode waterfall dengan penambahan pencarian data dan penyimpanan sertifikat dalam sistem pada Panti Sosial Harapan Mulia sehingga mempercepat proses kerja karyawan dan pengelolaan datanya lebih efisien dan efektif.

\section{BAHAN DAN METODE}

\section{A. Teknik Pengumpulan Data}

Untuk mendapat data-data yang menunjang teknik yang dilakukan adalah metode observasi, yaitu pengamatan secara langsung terhadap kegiatan sistem pendataan warga binaan pada Panti Sosial Harapan Mulia. Kemudian metode wawancara, yaitu melakukan wawancara langsung untuk mendapatkan informasi secara lengkap mengenai data dan kegiatan warga binaan Panti Sosial Harapan Mulia. Selanjutnya metode studi pustaka (library method), yaitu mendapatkan sumber data dari berbagai sumber dengan cara mengumpulkan referensi yang menunjang melalui buku, jurnal, majalah dan sumber lainnya yang mendukung penelitian.

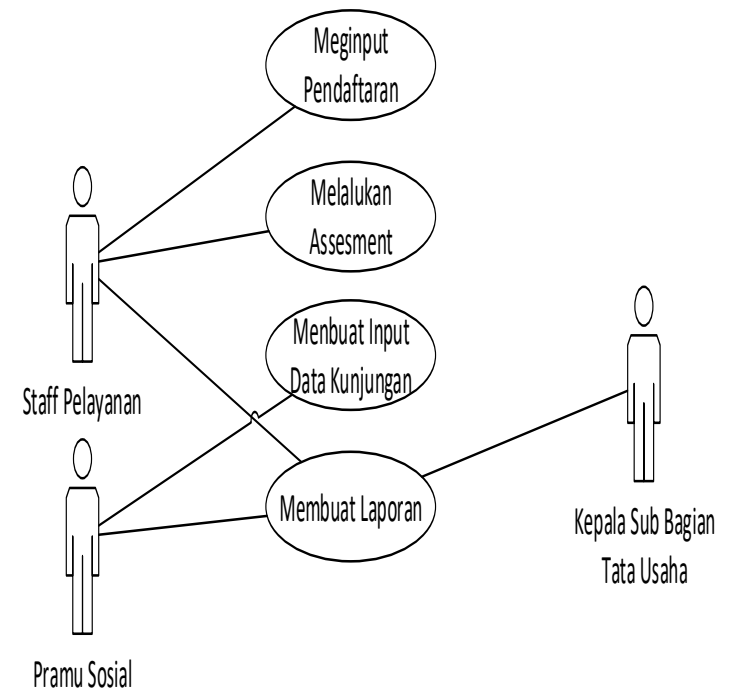

Gambar 1. Use Case Diagam

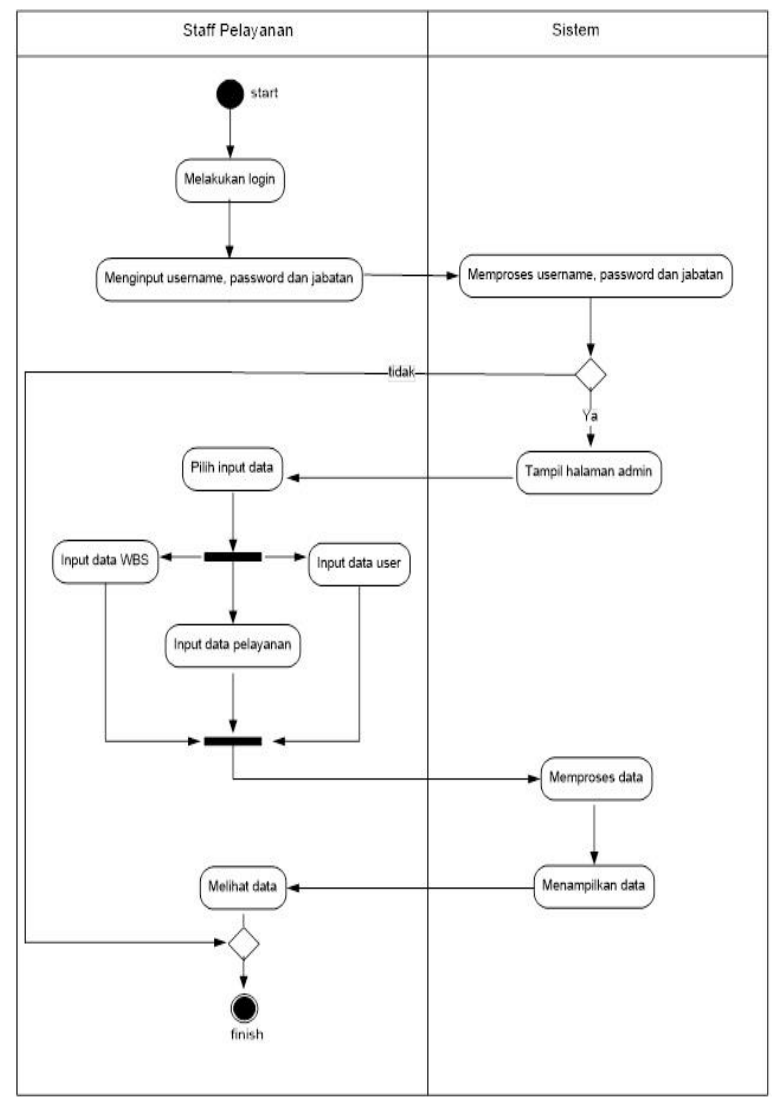

Gambar 2. Diagram Activity Staff Pelayanan 


\section{B. Metode Penelitian}

Metode yang digunakan pada pengembangan perangkat lunak ini menggunakan model waterfall, berikut tahapannya (Sukamto \& Shalahudin, 2016):

1. Analisa Kebutuhan

Pengumpulan data diperoleh melalui penelitian dan wawancara dengan menggali informasi mengenai sistem informasi pelayanan warga bina sosial pada Panti Sosial Harapan Mulia. Sistem yang digunakan sudah baik, tetapi terdapat kekurangan pencarian data (search) untuk pramu sosial warga bina sosial telah selesai di bina selama 6 (enam) bulan disisilain sertifikat belum disimpan dalam database.

2. Desain

Mengembangkan Perancangan Sistem Pelayanan Sosial dengan menggunakan Antar muka (interface), UML (Unified Modelling Language), Entity Relationship Diagram(ERD), logical Record Structure (LRS)

3. Pembuatan Kode Program

Tahap Pengkodean ini harus dipindahkan ke dalam perangkat lunak. Hasil dari tahapan ini adalah program sesuai dengan perancangan sistem yang telah dibuat pada tahap perancangan sistem dan perangkat lunak.

4. Pengujian

Pada tahapan ini penulis akan melakukan pengujian terhadap sistem yang telah dibuat untuk memastikan aplikasi yang dibuat sesuai dengan kebutuhan Panti Sosial Bina Karya Harapan Mulia.

5. Pendukung (support)

Tidak menutup kemungkinan sebuah perangkat lunak mengalami perubahan ketika sudah dikirim user. Perubahan terjadi karena adanya kesalahan yang muncul dan tidak terdeteksi saat pengujian atau perangkat lunak harus beradaptasi dengan linhkunhan baru. Pada tahap ini proses akan dilakukan kembali sesuai metode waterfall.

\section{HASIL DAN PEMBAHASAN}

Proses interaksi antara Staff Pelayanan, Pramu Sosial dan Kepala Sub Bagian Tata Usaha dalam Sistem Informasi Pelayanan Panti Sosial Harapan Mulia diseskripsikan pada usecase Gambar 1. Aliran kerja dalam Sistem Informasi Pelayanan Panti Sosial untuk staff pelayanan digambarkan pada diagram activity Gambar 2 . Aliran kerja dalam Sistem Informasi Pelayanan Panti Sosial untuk pramu sosial digambarkan pada diagram activity Gambar 3. Aliran kerja dalam Sistem Informasi Pelayanan Panti Sosial untuk kepala Sub Bagian Tata Usaha digambarkan pada diagram activity Gambar 2.
Perancangan database menggunakan Entity Relationship Diagram untuk menjelaskan relasi pada setiap entity yang ada pada Sistem Informasi Pelayanan Panti Sosial Harapan Mulia (Gambar 5) dan LRS pada Gambar 6.

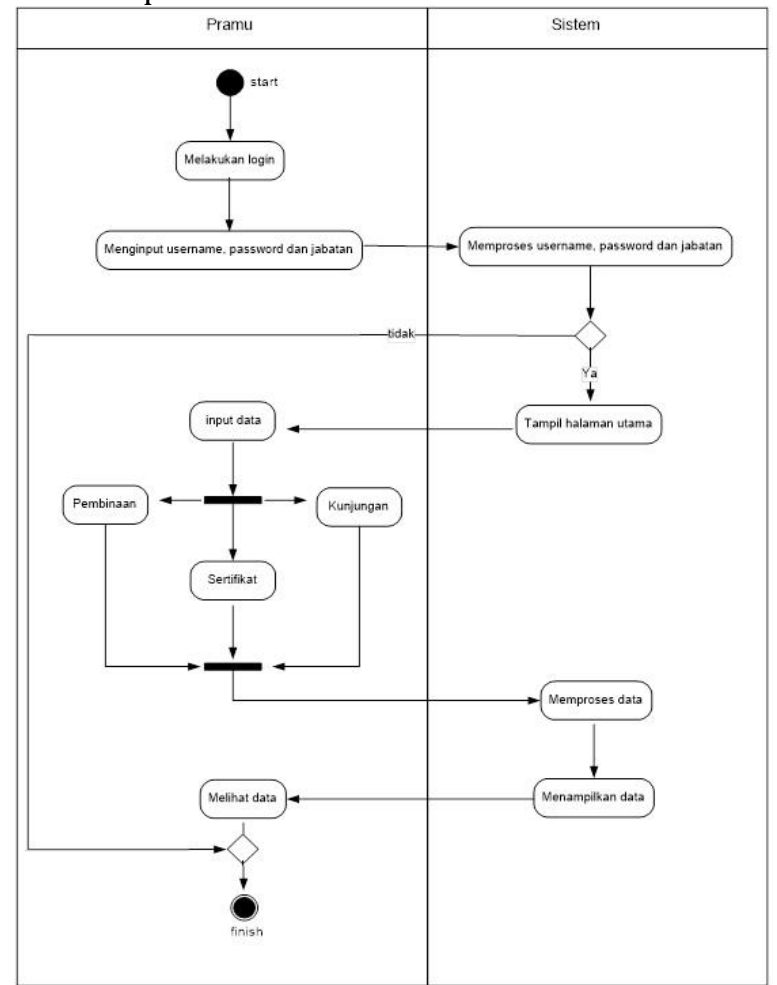

Gambar 3. Diagram Activity Pramu Sosial

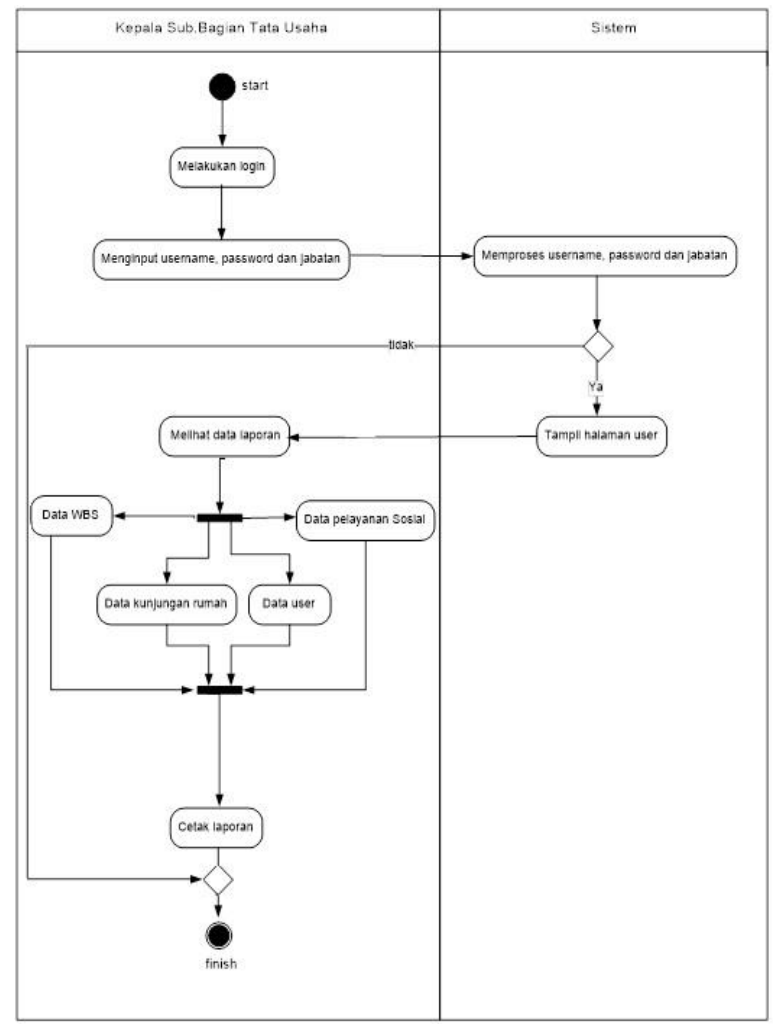

Gambar 4. Diagram Activity Kepala Sub Bagian Tata Usaha 


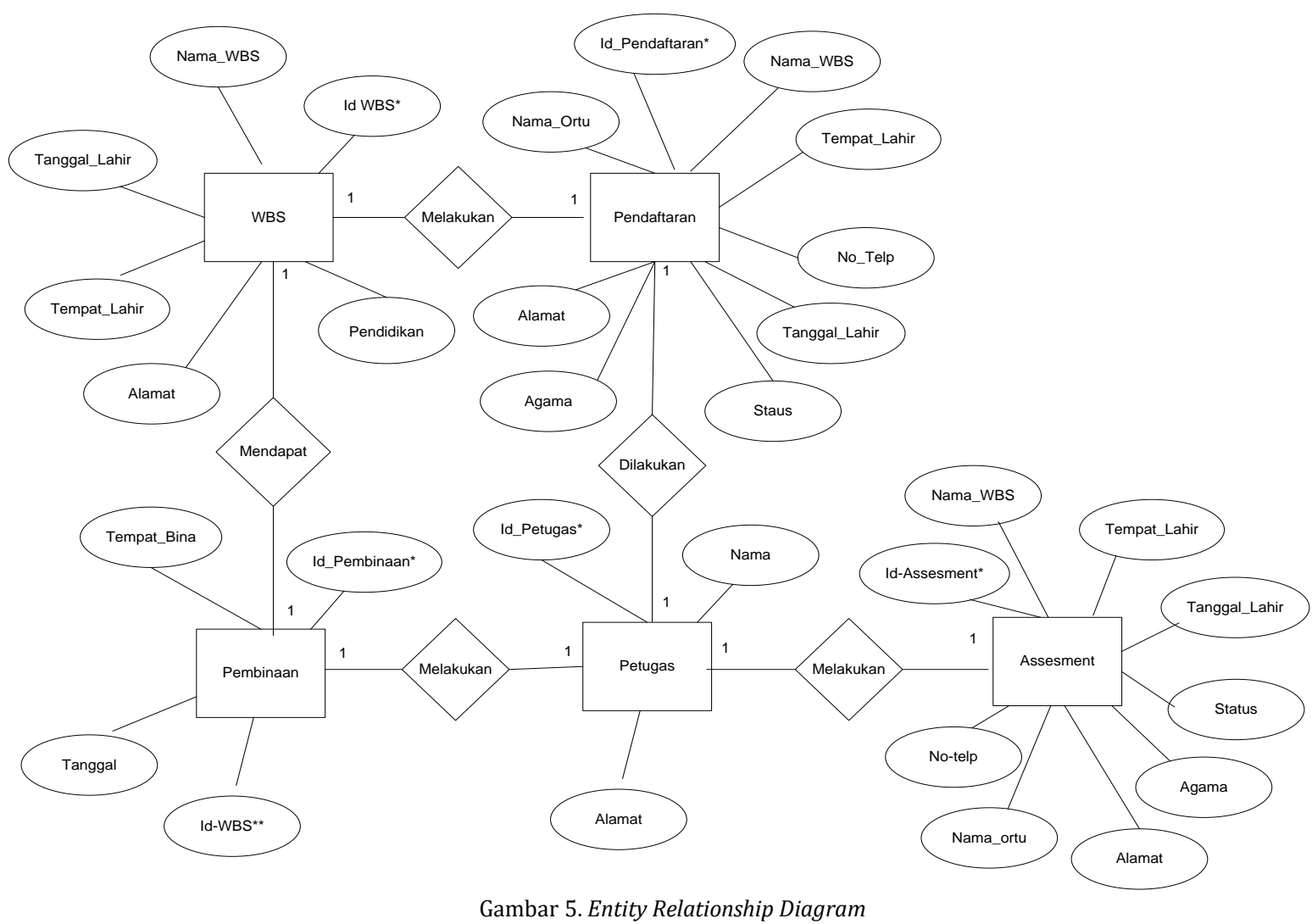

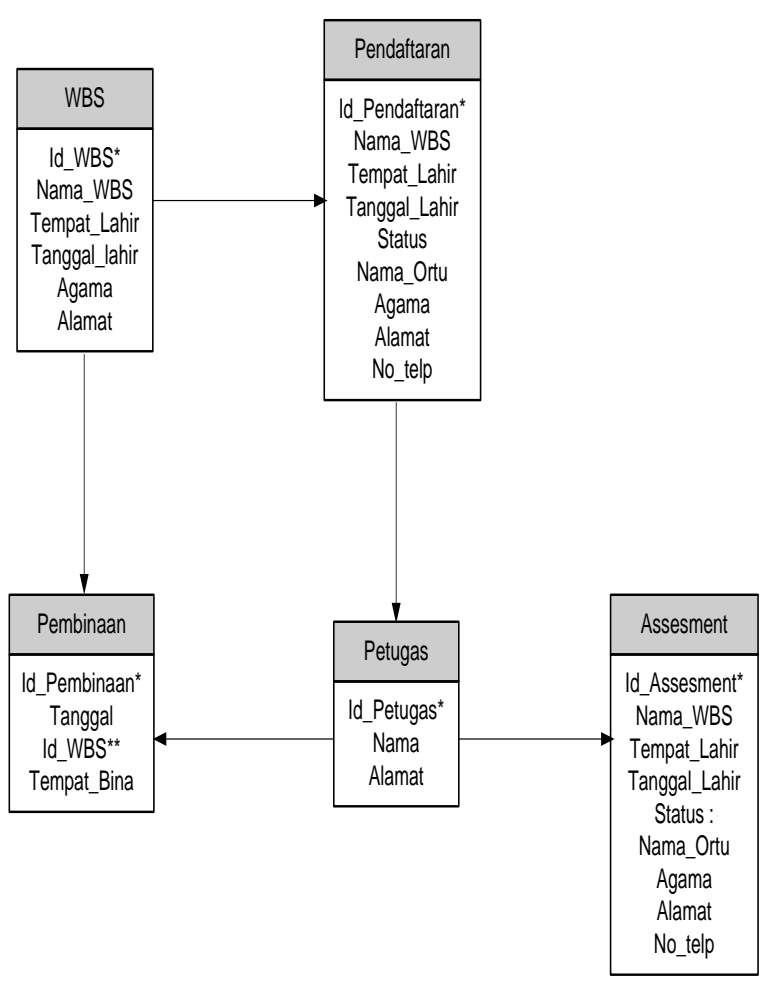

Gambar 6. Logical Record Structured
Tampilan Sistem Informasi Aplikasi Pelayanan Data Gambar 7 merupakan tampilan pada saat pertama kali program dijalankan yang merupakan tampilan menuutama dari Sistem Informasi Aplikasi Pelayanan Data Panti Sosial Harapan Mulia. Pada menu ini terdapat tulisan Selamat Datang dan pilihan masuk disini untuk ke halaman atau menu berikutnya.

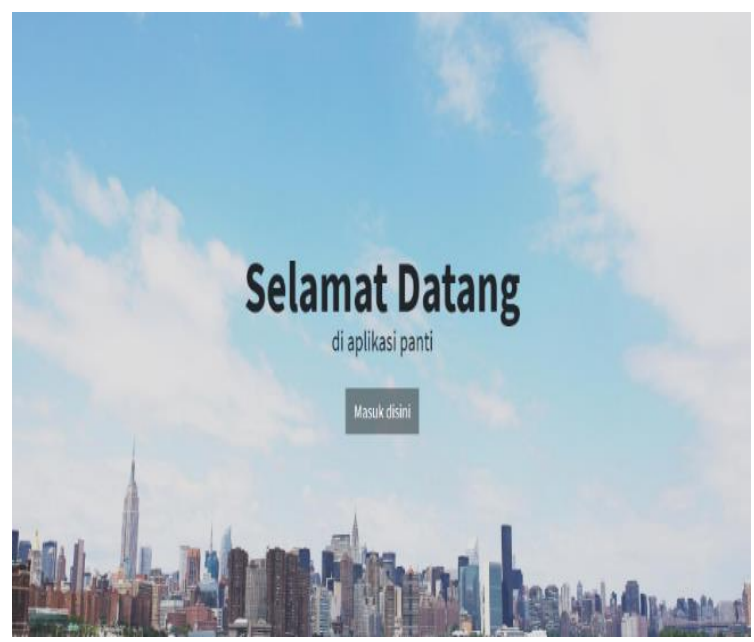

Gambar 7. Tampilan Awal Program 


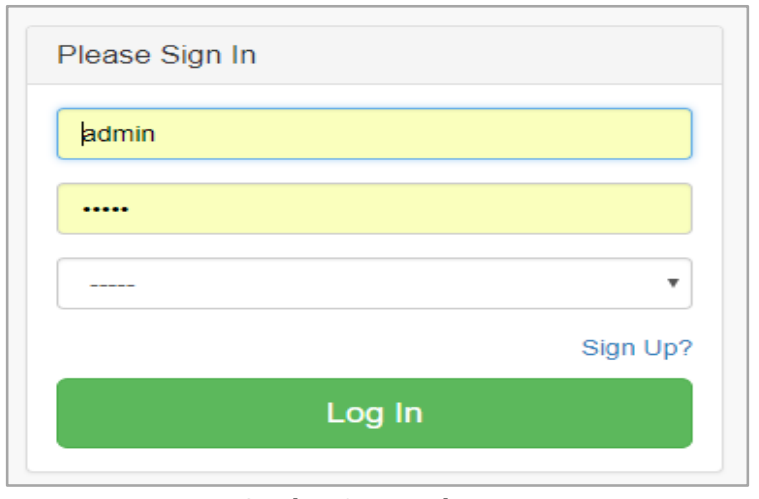

Gambar 8. Tampilan Login
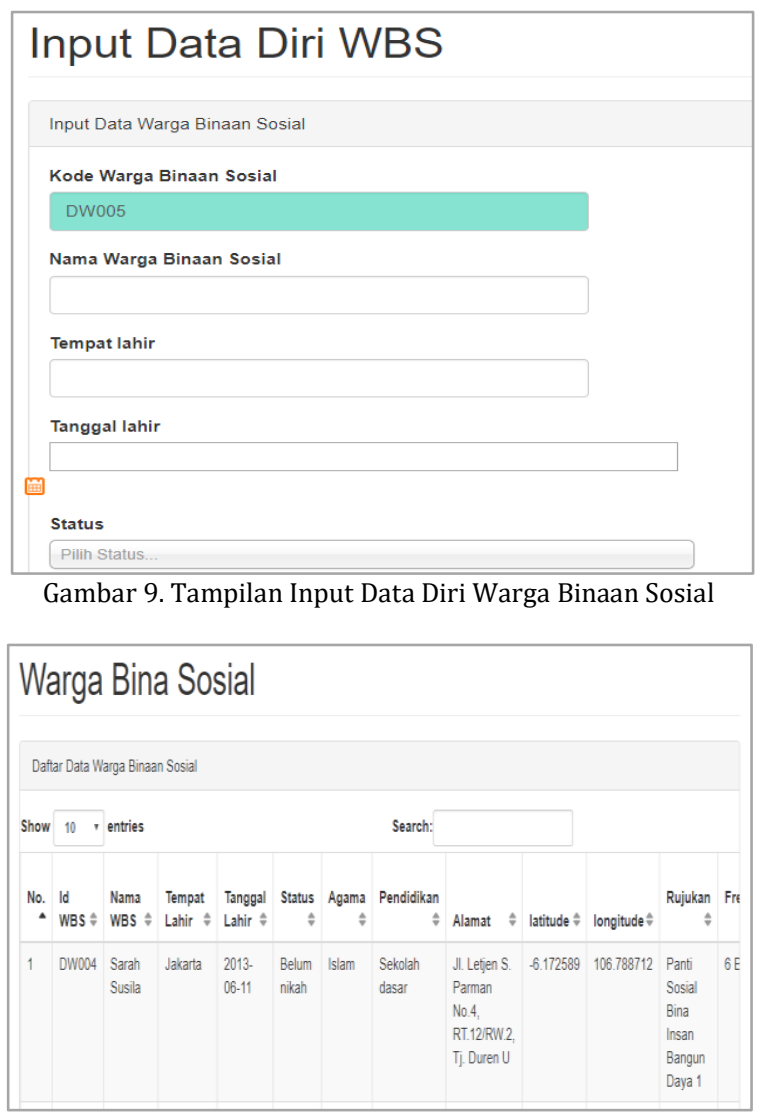

Gambar 10. Tampilan Pencarian Data Warga Bina Sosial

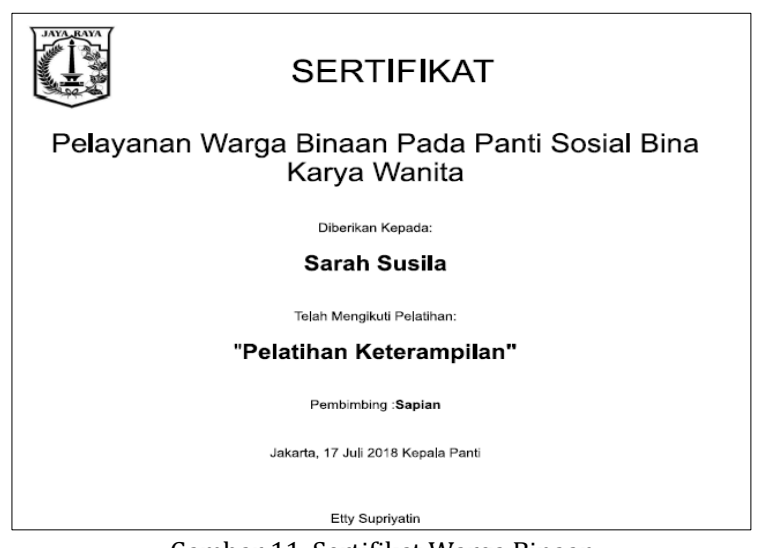

Gambar 11. Sertifikat Warga Binaan
Gambar 8 merupakan tampilan Menu Login pada saat user login ke sistem. Cara login awal ke Sistem Informasi Aplikasi Pelayanan Data Panti Sosial Harapan Mulia dengan menggunakan user dan password kemudian klik log in.

Gambar 9 merupakan tampilan sub menu input data warga binaan sosial. Pada tampilan ini terdapat form isian data warga binaan sosial yang terdiri dari kode warga binaan sosial, nama warga binaan sosial, tempat lahir, tanggal lahir dan status.

Gambar 10 merupakan tampilan sub menu daftar data warga binaan sosial yang merupakan output data warga binaan yang sudah diinput sebelumnya, dan pada sub menu daftar warga binaan sosial ini sudah ditambahkan fasilitas pencarian data yang bertujuan untuk mempermudah user dalam mencari data warga binaan.

Gambar 11 merupakan tampilan sub menu sertifikat yang telah ditambahkan pada program sehingga staff pelayanan bisa membuat sertifikat dengan cepat dan tepat dan sertifikat akan diberikan pada warga binaan sosial Harapan Mulia yang telah mengikuti pelatihan ketrampilan.

\section{KESIMPULAN}

Dengan menambahkan fitur pencari pada Sistem Pelayanan Data Panti Sosial mempermudah Panti Sosial Harapan Mulia dalam mencari data warga binaan sehingga pekerjaan karyawan lebih efisien dan efektif, dan dengan menggunakan penyimpan data sertifikat dalam sistem database akan mempermudah Panti Sosial dalam mengelola data Sertifikat warga binaan dan dengan adanya pembuatan sertifikat secara online akan mempermudah Panti Sosial dalam mencetak sertifikat secara online.

\section{REFERENS}

Afrizal, A. S. (2017). Rancang Bangun Aplikasi Pembelajaran Dasar Pemrograman Berbasis Mobil Phone. TIPS Politeknik Sekayu , VI No.1, 1-19.

Aprianti, W., \& Maliha, U. (2016). Sistem Informasi Kepadatan Penduduk Kelurahan atau Desa Studi Kasus pada Kecamatan Bati-bati Kabupaten Tanah Laut. Sains dan Informatika , 2, 21-28.

Destrianti, F., \& Harnani, Y. (2018). Studi Kualitatif Pekerja Seks (PSK) di Daerah Jondul Kota Pekanbaru. Endurance, 3(2), 302-312. 
Harison, \& Syarif, A. (2016). Sistem Informasi Geografis Sarana Pada Kabupaten Pasaman Barat. Teknoif, 4 (2), 40-50.

Setiawan, A. B. (2015). Ekosistem Penyelenggaraan Sertifikat Elektronik dalam Sistem Perdagangan Elektronik. Jurnal Penelitian dan Pengembangan Komunikasi dan Informatika , 6(2), 15-27.

Simarmata. (2007). Perancangan Basis Data. Jogjakarta: Andi.

Soebijoto, H. (2018). Begini Suasana Pelatihan Ketrampilan warga Binaan di PSBKW Harapan Mulya Kedoya. Diambil dari : https://wartakota.tribunnews.com/2018/ 09/27/begini-suasana-pelatihanketerampilan-warga-binaan-di-psbkwharapan-mulya-kedoya?page $=2$. September 2018).
Sukamto, R., \& Shalahudin, M. (2016). Rekayasa Perangkat Lunak. Bandung: Informatika.

Susetyo, D. B., \& Sudiantara, Y. (2015). Konsep Diri Pada Pekerja Seks Komersial. Psikodimensia , 14/2, 27-40. 